\title{
Dispersal and Movement Mechanisms of Phytophthora capsici Sporangia
}

\author{
L. L. Granke, S. T. Windstam, H. C. Hoch, C. D. Smart, and M. K. Hausbeck
}

First, second, and fifth authors: Department of Plant Pathology, Michigan State University, East Lansing, MI 48824; and third and fourth authors: Cornell University, Department of Plant Pathology and Plant-Microbe Biology, NYSAES, Geneva, NY 14456. Accepted for publication 22 July 2009.

\section{ABSTRACT}

Granke, L. L., Windstam, S. T., Hoch, H. C., Smart, C. D., and Hausbeck, M. K. 2009. Dispersal and movement mechanisms of Phytophthora capsici sporangia. Phytopathology 99:1258-1264.

Understanding the mechanisms of Phytophthora capsici sporangial dissemination is paramount to understanding epidemic initiation and development. Direct laboratory observations showed $P$. capsici sporangial dispersal occurred in water with capillary force, but did not occur in response to wind or a reduction in relative humidity. Atmospheric sporangial concentrations were monitored under field conditions using a volumetric spore sampler in a commercial cucurbit field and in an experimental setting where copious sporangia were continuously available in close proximity to the spore trap. Dispersal was infrequent $(0.7 \%$ of total hours monitored) during sampling in a commercial field; 14 sporangia were detected during a 7.5 -week sampling period. In the experimental field situation, dispersal occurred in $4.6 \%$ of the hours sampled and 438 sporangia were impacted onto tapes during a 7-week sampling period. Airborne sporangial concentrations were positively associated with rainfall at both sites, but not vapor pressure deficit. Furthermore, in the experimental field situation, wind speed was not significant in regression analysis. Wind speed was not measured in the commercial field. Hence, both direct laboratory observations and volumetric spore sampling indicate that dispersal of sporangia via wind currents is infrequent, and sporangia are unlikely to be naturally dispersed among fields by wind alone.
The oomycete plant pathogen Phytophthora capsici Leonian has a large host range including vegetable crops in the Cucurbitaceae and Solanaceae (11) as well as snap bean (Phaseolus vulgaris L.) (15), lima bean (Phaseolus lunatus L.) (8), Fraser fir (Abies fraseri (Pursh) Poir.) (25), and weed hosts (13). P. capsici has a worldwide distribution (11) and may be a significant limiting factor to vegetable production (17). Although $P$. capsici is a soilborne pathogen, it also causes significant disease on aerial plant tissues including rot of the fruit, stem, and crown and blighting of the foliage, in addition to root rot $(17,27)$. P. capsici may generate copious amounts of asexually produced caducous sporangia on a host surface after infection has been established. Mature sporangia may germinate directly via formation of one to several germ tubes or, when in contact with free water, will differentiate into 20 to 40 biflagellate motile zoospores (3). Abundant sporangial production is a key ecological trait that allows $P$. capsici to exhibit rapid polycyclic disease development under favorable conditions (17).

Since spores are microscopic and hence difficult to detect, especially at low concentrations (1), most evidence for $P$. capsici dispersal has been indirect, either through inferences based on spatial analysis of disease patterns $(26,28)$ or genetic diversity data $(22,23)$. Studies in which the genetic diversity of $P$. capsici populations in Michigan was examined suggested that long-distance dispersal of sporangia is uncommon $(22,23)$. Elucidation of the mechanisms of sporangial dissemination is critical to fully understanding the progress of an epidemic within a field. Several dispersal mechanisms have been proposed for $P$. capsici, including transfer via (i) water movement down rows, (ii) rain splash or

Corresponding author: M. K. Hausbeck; E-mail address: hausbec1@msu.edu

doi:10.1094/PHYTO-99-11-1258

(C) 2009 The American Phytopathological Society wind-blown rain, (iii) air, or (iv) movement by humans or invertebrate activity $(17,26)$. Analysis of spatial patterns of disease support water movement as a major dispersal mechanism for $P$. capsici propagules $(26,28)$. Splash dispersal has been observed for several Phytophthora spp. including $P$. nicotianae, $P$. palmivora, and $P$. infestans $(30,33)$, but has not been directly examined for $P$. capsici even though it is assumed to be a means of pathogen spread. Although it has been speculated that local aerial dispersal of $P$. capsici propagules may occur (27), previous studies have described aerial dispersal as unimportant $(29,32)$. To our knowledge, the only study that has attempted to directly sample aerially dispersed $P$. capsici propagules used media-filled petri plates affixed to stakes in a pepper field during an active $P$. capsici epidemic (32). This study found that aerial dispersal occurred rarely, and dispersal in dry air was only detected when plates were within $5 \mathrm{~cm}$ of a heavily sporulating source.

$P$. infestans, the causal agent of potato late blight, is the most well studied Phytophthora sp. with regards to aerial dispersal $(7,19,21)$. It has long been known that $P$. infestans sporangiophores display hygroscopic movement as relative humidity decreases during the morning hours and actively release sporangia $(9,19,20)$. Sporangia are subsequently carried away from the inoculum source by wind (2). This mode of dispersal is also seen in downy mildew pathogens such as Bremia lactucae, the causal agent of lettuce downy mildew (31). Because $P$. infestans and $P$. capsici both infect and form sporangia on above-ground plant tissue, growers sometimes postulate that $P$. capsici sporangia may be dispersed in a manner similar to that of $P$. infestans. To our knowledge, no studies have directly examined $P$. capsici sporangial detachment and dispersal in response wind and water. The objectives of our study were to directly observe whether a change in relative humidity, direct wind, or water combined with capillary force enables detachment and transport of $P$. capsici sporangia, and assess the probability of aerial dispersal in commercial and experimental field situations. 


\section{MATERIALS AND METHODS}

Growth and maintenance of Phytophthora isolates. $P$. capsici isolates SP98 and 0664-1 were maintained at room temperature $\left(25 \pm 2{ }^{\circ} \mathrm{C}\right)$ under continuous fluorescent lighting on UCV8 (160 ml of unclarified V8 juice, $840 \mathrm{ml}$ of distilled water, $30 \mathrm{mM}$ $\mathrm{CaCO}_{3}$, and $1.5 \%$ agar) and were transferred to fresh UCV8 weekly. SP98 (A2 mating type, sensitive to mefenoxam) was isolated from pumpkin (Cucurbita pepo L.) in Michigan, and 0664-1 (A1 mating type, sensitive to mefenoxam) was isolated from pepper (Capsicum annuum L.) in New York. Isolate notation refers to the culture collections maintained in the laboratories of M. K. Hausbeck at Michigan State University and C. D. Smart at Cornell University. $P$. infestans clonal lineage US-11 was obtained from the laboratory of W. E. Fry at Cornell University and was maintained on detached tomato leaflets (Solanum lycopersicum L. cv. Sunchief).

Inoculation. Detached pickling cucumber fruits (Cucumis sativus L., $10 \pm 1 \mathrm{~cm}$ long) were surface disinfested with a $10 \%$ bleach $(0.62 \% \mathrm{NaClO})$ solution for $10 \mathrm{~min}$, rinsed with distilled water, blotted dry, and placed in a sterile humid chamber $(23 \times$ $10 \times 31 \mathrm{~cm}$ lidded clear plastic box with moist paper towels in the bottom to maintain humidity) before inoculation with $P$. capsici zoospores. Zoospore suspensions were prepared by flooding actively sporulating (4 to 7 days old) $P$. capsici cultures with sterile distilled water and incubating the plates at $4{ }^{\circ} \mathrm{C}$ for $45 \mathrm{~min}$ followed by $30 \mathrm{~min}$ at room temperature. The concentration of zoospores was determined with a hemacytometer and adjusted to $2.5 \times 10^{6}$ zoospores $/ \mathrm{ml}$ for each isolate. Three $10-\mu$ l droplets of zoospore suspension were used to inoculate each cucumber fruit. Cucumbers were incubated at room temperature under continuous fluorescent lighting until copious sporangia were detectable by light microscopy, approximately 72 to $96 \mathrm{~h}$ postinoculation (Fig. 1 A to $\mathrm{C})$.

Tomato leaflets were inoculated by firmly pressing healthy leaflets against ones with lesions containing $P$. infestans sporangia. Inoculated leaflets were incubated at $19^{\circ} \mathrm{C}$ in plastic petri dishes $(100 \times 15 \mathrm{~mm}$ round $)$ with either water agar or moist filter paper in the lids to maintain humid conditions (incubation units) and were used once abundant sporulation was apparent, which was a minimum of 4 days postinoculation.

Fabrication of minichambers for direct observation of $\boldsymbol{P}$. capsici sporangia. For preparation of minichambers, polydimethylsiloxane (PDMS, Sylgard 184, Dow Corning, Midland, MI) was poured over a plastic petri dish $(100 \times 100 \times 15 \mathrm{~mm})$ and cured at $60^{\circ} \mathrm{C}$ for $1 \mathrm{~h}$. Spacers were used to maintain a PDMS thickness of $5 \mathrm{~mm}$. Following curing, a square of PDMS was cut into an $\mathrm{H}$-shape and released from the petri dish. To create the bottom half of the chamber, the PDMS and a microscope slide $(51 \times 76 \mathrm{~mm})$ were covalently bonded to each other following exposure to an air plasma (10). Openings were bored through the PDMS, and stainless steel tubing (Small Parts Inc., Miramar, FL) was inserted and sealed with unpolymerized PDMS, which was heat-cured and reinforced with Torr Seal epoxy (Varian Inc., Lexington, MA) to create an inlet and outlet for wind at each end of the chamber. A cover glass was placed on the minichamber and held in place with microscope stage clips to seal the chamber during observation. Wind was generated using a TopFin XP-125 aquarium pump (PetSmart, Phoenix, AZ) and humidified by passing air through moist cheesecloth loosely packed into a humidity chamber to minimize sporangia dehydration. The air flow was adjusted to $1.50 \pm 0.06$ liters/min using a flow meter (Dwyer Instruments, Michigan City, IN). Vinyl and rubber tubing was used to route the wind from the pump through the humidity chamber and into the minichamber.

Direct observation of sporangia exposed to wind and water. Sporangia were directly observed with an Olympus SZX12 dissecting microscope (Olympus America Inc., Center Valley, PA) with an Intralux 4000 fiber optic light source (Volpi, Switzerland) for overhead illumination or an Olympus IMT-2 inverted compound microscope. Images and real-time movies were captured using a CoolSnap Cf camera (Photometrics, Tucson, AZ). MetaMorph software (Universal Imaging, Dowingtown, PA) was used for shutter control, image capture, and subsequent image processing. Individual video frames were obtained from a streaming video sequence.

Tomato leaflets with actively sporulating $P$. infestans were used as a positive control to demonstrate that sporangial dispersal in

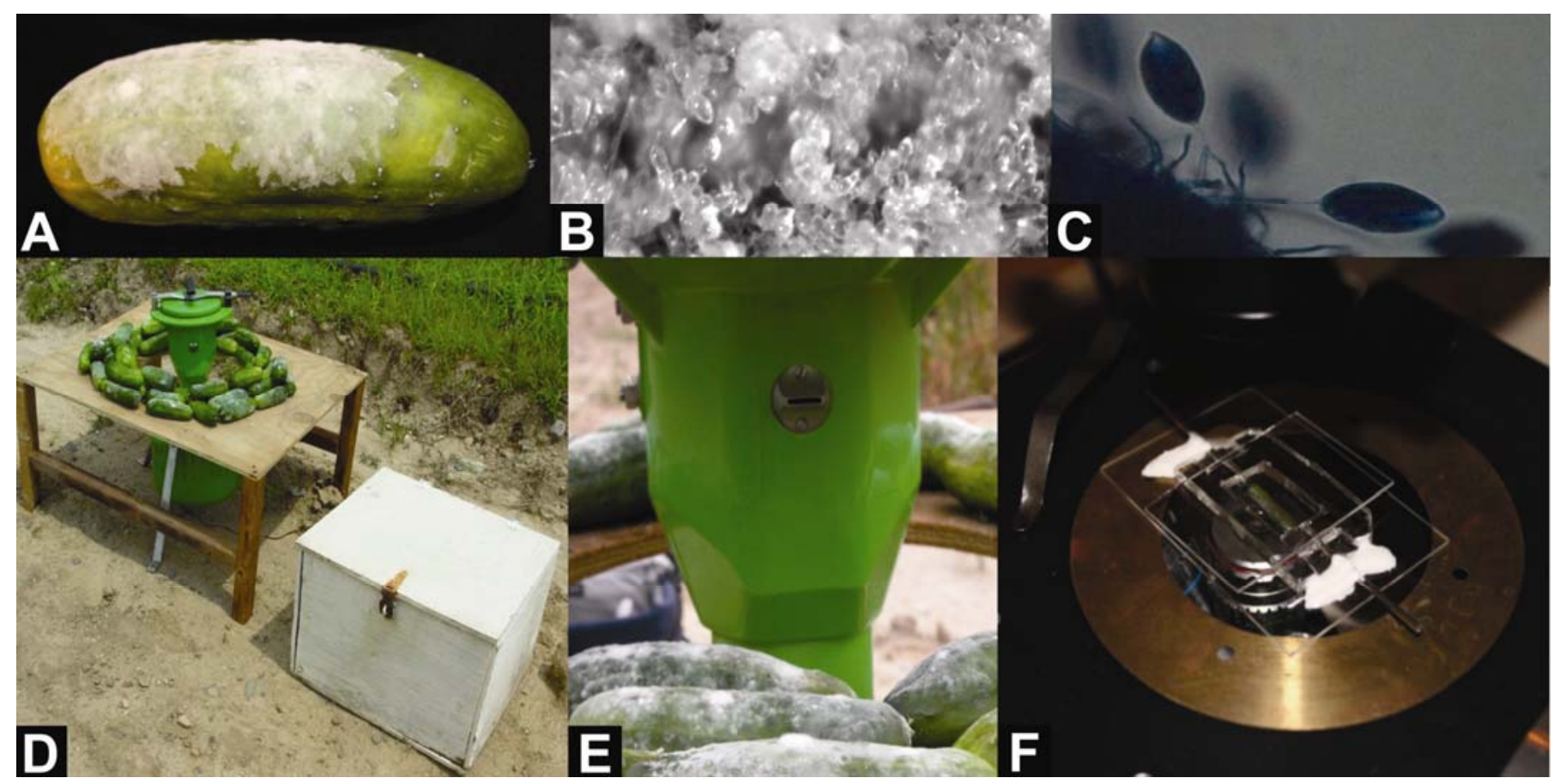

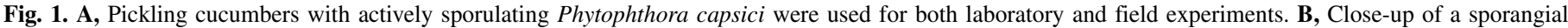

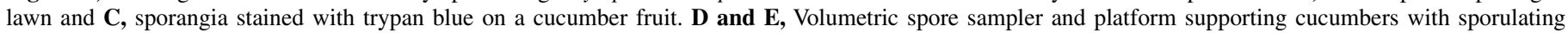
$P$. capsici in a field. F, Minichamber (on inverted compound microscope stage) used for direct observations of the effect of wind on $P$. capsici sporangia. 
the laboratory setting could be directly observed. The top of the incubation unit was removed, which allowed low humidity ambient air to enter the unit resulting in a humidity decrease in the unit. Sporangia were directly observed and images were captured as described above. Intact pickling cucumber fruits with $P$. capsici sporangia were removed individually from a moist incubation chamber and placed onto a glass cover slide $(103 \times 83 \mathrm{~mm})$ to observe $P$. capsici sporangia after a reduction in relative humidity. The fruit were placed on the glass cover slide that was scanned before and after sporangial observation to ensure all dispersal events were detected. Sporangia were observed for 2 min with images captured as described above. A small piece of tissue containing sporangia was excised from the fruit and placed into a minichamber. Sporangia were observed using a compound microscope for 2 min while 1.5 liters/min of air was pumped through the minichamber (Fig. 1F). The glass bottom of the minichamber was scanned before and after observation of sporangia to determine if any undetected dispersal occurred. Finally, two small pieces of tissue containing sporangia were excised from the same fruit and placed onto a glass microscope slide 1 to $2 \mathrm{~mm}$ apart with the infected surfaces facing each other. A coverslip was placed on top of the tissue pieces and 10 to $50 \mu$ of water was pipetted between the pieces allowing capillary action to draw the water down the length of the pieces. The sporangia were directly observed for dispersal in water as described above. At least 30 observations were made for each potential dispersal event.

Monitoring of atmospheric sporangial concentrations of $\boldsymbol{P}$. capsici under field conditions. Atmospheric concentrations of $P$. capsici sporangia were determined with a Burkard 7-day volumetric spore sampler (Burkard Manufacturing Co. Ltd., Rickmansworth, Hertfordshire, UK). The sampling airflow rate was 10 liters/min, and the sampler was set to allow free movement according to wind direction so that the orifice faced the prevailing wind. Sporangia were impacted onto tapes coated with an adhesive mixture of petroleum jelly and paraffin $(9: 1, \mathrm{wt} / \mathrm{wt})$ dissolved in sufficient toluene to result in a thick, liquid consistency. Tapes were removed weekly, cut into $48 \mathrm{~mm}$ lengths, scored at hourly intervals, stained with aniline blue in glycerol $(0.14 \mathrm{mg}$ of aniline blue, $20 \mathrm{ml}$ of distilled water, $15 \mathrm{ml}$ of glycerol, $10 \mathrm{ml}$ of $85 \%$ lactic acid), mounted on glass slides under $22 \times 50-\mathrm{mm}$ coverslips, and sealed using Cytoseal (Richard-Allan Scientific, Kalamazoo, MI). Slides were scanned, and P. capsici sporangia were examined at $400 \times$ magnification and identified based on morphological characteristics (34).

Atmospheric sporangial concentrations were monitored in a commercial cucurbit field and in an experimental field situation. Spore sampling was conducted for a period of 7.5 weeks (16 June to 8 August 2006) at a commercial farm in Cass County, MI planted to cucurbits (acorn squash (Cucurbita pepo L. cv. Table Ace) followed by cucumber (cv. Cobra)). Fungicides were applied to acorn squash in support of fungicide research that was conducted in this field and to the cucumber crop according to commercial recommendations. Severe disease was observed in the acorn squash, and more than $75 \%$ of plants were dead by 26 July when the spore trap was moved to cucumber. Atmospheric con-

TABLE 1. Number of direct observations of Phytophthora infestans or $P$. capsici sporangia made with a dissecting or inverted compound microscope ${ }^{\mathrm{a}}$

\begin{tabular}{llllll}
\hline & & & \multicolumn{3}{c}{$\begin{array}{c}\text { Observations } \\
\text { (\% with dispersal) }\end{array}$} \\
\cline { 3 - 6 } Pathogen & $\begin{array}{c}\text { Lineage/ } \\
\text { isolate }\end{array}$ & Host tissue & RH & Wind & Water \\
\hline$P$. infestans & US-11 & Tomato leaflets & $40(100)$ & n/a & n/a \\
$P$. capsici & SP98 & Cucumber fruit & $30(0)$ & $30(0)$ & $30(100)$ \\
$P$. capsici & $0664-1$ & Cucumber fruit & $30(0)$ & $30(0)$ & $30(100)$ \\
\hline
\end{tabular}

a Each cluster of sporangia on an individual leaflet or cucumber was observed until dispersal occurred or up to $2 \mathrm{~min}$. $\mathrm{RH}=$ a reduction in relative humidity. $\mathrm{n} / \mathrm{a}=$ not applicable. centrations of sporangia were monitored for 7 weeks (19 July to 16 September 2008) in an experimental field setting at the MSU Muck Soils Research Farm, Laingsburg, MI. At this site, infected cucumbers with sporulating $P$. capsici (isolate SP98) were prepared as described above. Cucumbers were placed on a raised platform approximately 15 to $40 \mathrm{~cm}$ from the sampler so that infected tissue with the sporulating pathogen faced the Burkard spore sampler and was level with the sampler orifice (Fig. 1D and E). This configuration allowed for quantification of dispersal without the limitation of a canopy and with minimal spatial dilution effects. Fruit were replaced with new infected cucumbers with sporulating $P$. capsici triweekly to ensure that sporangia were constantly available. Cucumbers were checked for sporulating $P$. capsici with a dissecting microscope before and after placement in the field to ensure that copious amounts of sporangia were available for the entire monitoring period.

Collection of weather data and statistical analysis. Hourly meteorological data of temperature $\left({ }^{\circ} \mathrm{C}\right)$, relative humidity $(\%)$, and rainfall $(\mathrm{mm})$ were measured by a Watchdog model 450 data logger and tipping bucket rain gauge (Spectrum Technologies, Plainfield, IL) at the commercial field. Hourly meteorological data of air temperature $\left({ }^{\circ} \mathrm{C}\right)$, relative humidity $(\%)$, average and maximum wind speed $(\mathrm{m} / \mathrm{s})$, and rainfall $(\mathrm{mm})$ were measured by an automatic weather station belonging to the Michigan Automated Weather Network at the experimental field. Vapor pressure deficit (VPD, $\mathrm{kPa}$ ) was calculated for both sites using temperature and relative humidity values (24). Statistical analyses were performed using the SAS statistical package version 9.1 (SAS Institute, Inc., Cary, NC). The PROC CORR procedure was used to determine any positive or negative correlations among daily cumulative atmospheric sporangial concentration, daily cumulative rainfall, and daily average VPD for the commercial field and to determine correlations between daily cumulative atmospheric sporangial concentration, daily cumulative rainfall, daily average VPD, and daily average wind speed prior to regression analysis for the experimental field situation. Autocorrelation in the data set was characterized using ITSM 2000 software and was detected for the experimental field situation (attached to (4)). Regression analysis of data from the commercial field was not completed as the assumptions of regression could not be met. The PROC AUTOREG procedure of SAS was used for regression analysis of data from the experimental field to appropriately address the autocorrelation detected in this data set. The AUTOREG procedure calculates the equivalent of the least square parameter estimates of a regression model when the data are time series and the error term is an autoregressive process. The AUTOREG procedure uses the two-step full transform estimation method (16) to correct for the lack of independence through time of the error term of time series data. Variables with $P \leq 0.05$ were considered statistically significant. The final day of sampling at each site was not used in statistical analyses because less than $24 \mathrm{~h}$ of data were available for these days.

\section{RESULTS}

Direct observations of wind and water effects on dispersal. $P$. infestans sporangiophores displayed hygroscopic movement almost immediately after a reduction in relative humidity. In all cases where mature sporangia were present, dehiscence followed the twisting of sporangiophores under nearly still conditions (Table 1). All dispersal events took place within $60 \mathrm{~s}$ of a reduction in humidity, and could be clearly viewed by microscopy (Fig. 2 ). This validated that the methods used in this study were sufficient to directly observe sporangial dispersal. Dispersal of individual sporangia was rapid, often no longer than a single video frame (Fig. 2A and B). In contrast, $P$. capsici sporangiophores did not display hygroscopic movement upon a reduction in relative humidity, and dispersal was not observed (Table 1). Sporangia on 
the cucumber fruit surface were not dispersed in wind (Table 1, Fig. 3). However, water in combination with capillary force caused sporangia to readily detach from the fruit surface almost immediately upon wetting the cucumber fruit surface, and sporangia were transported in the water (Table 1, Fig. 4). Videos capturing these dispersal experiments may be viewed at the home page of M. K. Hausbeck.

Atmospheric $P$. capsici sporangial concentrations under field conditions. When atmospheric sporangial concentrations were monitored in a commercial cucurbit field, dispersal occurred during $0.8 \%$ of hours sampled (10 of $1,278 \mathrm{~h}$ ). The concentration of sporangia never exceeded 5 sporangia $/ \mathrm{m}^{3} / \mathrm{h}$ when dispersal was detected. In total, 14 sporangia were impacted onto tapes during the course of the 7-week sampling period. Only one sporangium was sampled during most $(80 \%)$ of the hours when dispersal was detected. In the experimental field situation (Fig. 1D), aerial dispersal occurred in $4.6 \%$ of the hours sampled (54 of $1,174 \mathrm{~h}$ ). The concentration of sporangia was low $\left(\leq 15\right.$ sporangia $\left./ \mathrm{m}^{3} / \mathrm{h}\right)$ for $80 \%$ of the occasions when dispersal was detected. Only 438 sporangia were impacted onto tapes over the course of the 7-week sampling period. No clear diurnal pattern was observed for sporangial dispersal at either site (data not shown).

Rainfall was significantly positively correlated $(r=0.57, P<$ $0.0001)$ with detection of sporangia in the commercial field. Rainfall was the only weather parameter that was significant in regression analysis $\left(\beta=3.57, R^{2}=0.68\right)$ for the experimental field situation. Dispersal occurred during $56 \%$ (5 of 9) of days with rainfall at the commercial farm and $56 \%$ (9 of 16) of days with rainfall at the experimental field (Fig. 5). Dispersal occurred during $42 \%$ ( 5 of 12) of days without rainfall at the commercial farm and $30 \%$ (9 of 30) of days without rainfall at the experimental field (Fig. 5). Vapor pressure deficit was not significant in correlation or regression analysis, respectively, for the commercial or experimental field. Wind speed was not measured in the

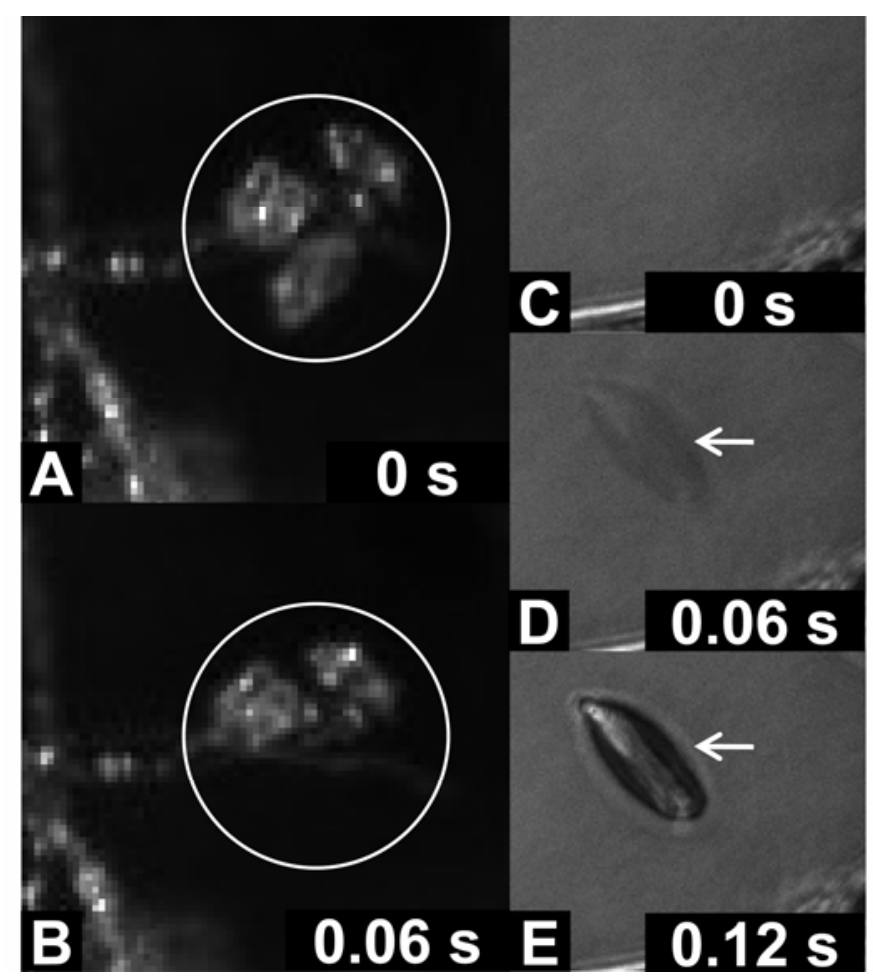

Fig. 2. A and B, Direct observation of individual Phytophthora infestans sporangia being dispersed and $\mathbf{C}$ to $\mathbf{E}$, settling on the bottom of the incubation unit. A sporangium in the circled cluster of sporangia in $\mathbf{A}$ is dispersed and absent in the subsequent video frame captured $0.06 \mathrm{~s}$ later in $\mathbf{B}$. A sporangium (arrow) in $\mathbf{E}$ attaches to the bottom of the incubation unit after its shadow is seen in the previous frame (D). commercial field and was not found to be significant in regression analysis for the experimental field.

\section{DISCUSSION}

This study suggests that dispersal of $P$. capsici sporangia via wind currents is infrequent and that sporangia are unlikely to be dispersed among fields by wind. This is in agreement with the conclusions of Lamour and Hausbeck $(22,23)$ from spatiotemporal genetic diversity data of populations of $P$. capsici in Michigan and Schlub (32), who investigated aerial dispersal in a pepper field with an active epidemic of Phytophthora blight.

Direct observations in the laboratory showed that sporangial dispersal occurred in water with capillary force, but did not occur

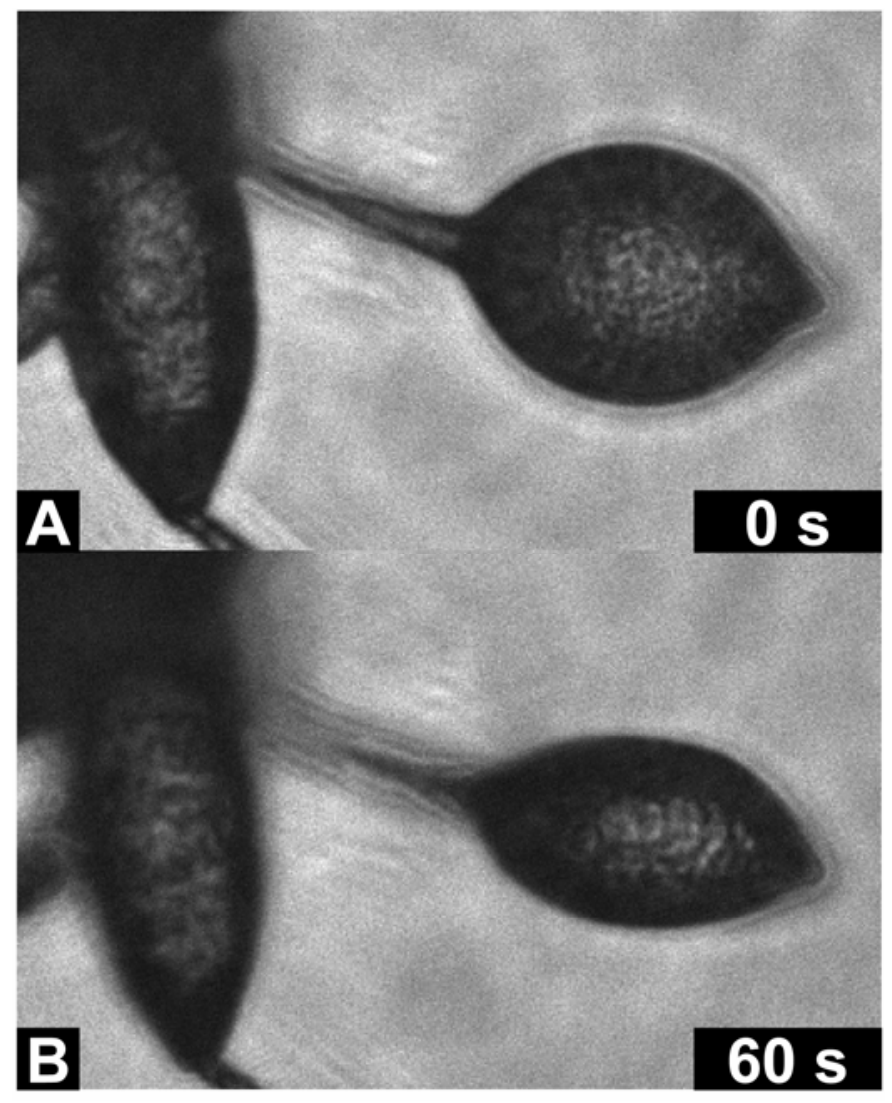

Fig. 3. A Phytophthora capsici sporangium on a piece of cucumber fruit $\mathbf{A}$, before and $\mathbf{B}$, after being exposed to 1.5 liters $/ \mathrm{min}$ of wind for $60 \mathrm{~s}$. No dispersal was observed. Note dehydration of sporangium.

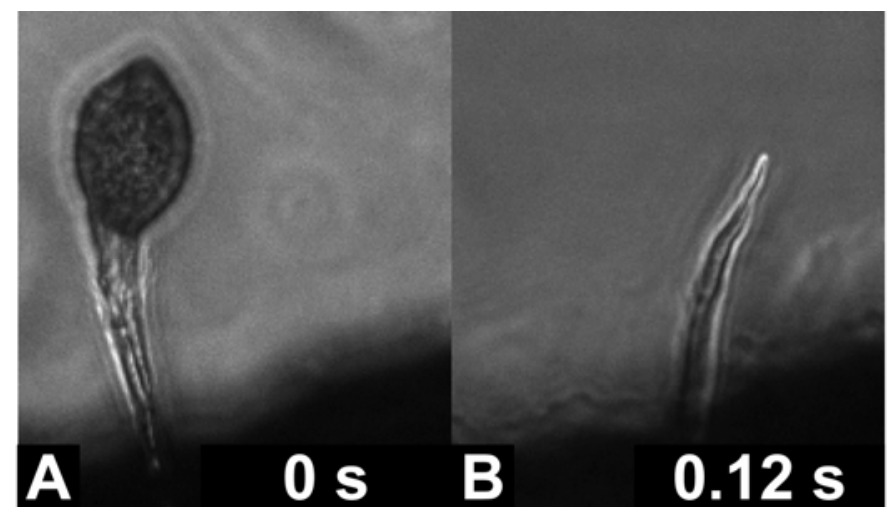

Fig. 4. A, A Phytophthora capsici sporangium before introducing water that is distributed via capillary force along the surface of a cucumber piece with the sporulating pathogen. B, The sporangium detaches and is dispersed in the water resulting in an empty sporangiophore. 
due to wind or a reduction in relative humidity. Laboratory results were confirmed in the field; volumetric spore sampling demonstrated aerial dispersal was a low frequency event, especially under commercial field production conditions. Furthermore, a very small amount of the total available sporangial load was dispersed. In the experimental field situation, a total of 438 sporangia were detected from an estimated minimum of 189 to 567 lesions throughout the 7-week sampling period. In comparison, up to 600,000 sporangia can be dislodged by water and mechanical force from one lesion with $P$. capsici sporulating profusely when a cucumber is inoculated and incubated as described above (data not shown). The escape of sporangia is limited by the presence of a canopy, and detached sporangia may be diluted during transport in the wind. These two limitations on detection were intentionally removed in the experimental field setting, but not at the commercial farm. In cucumber, the plant's foliage is typically asymptomatic and sporangia form primarily on fruit or occasionally at the plant's base. Thus, a reduced canopy is not common in cucumber fields with high disease pressure, and sporangia tend to be low in the canopy where the wind velocity is reduced as compared to the upper canopy (2). While some hosts such as pepper may display sporulation on tissue higher in the canopy (27), sporangia tend to be low in the canopy on the crown and/or fruit tissues of most infected host plants including acorn squash (17). When we sampled aerial sporangial dispersal from infected cucumbers placed on a platform without the limitation of a canopy (experimental field situation) few sporangia were trapped, and often these sporangia were detected in clusters. Clusters of sporangia should deposit close to the original source due to the increased settling speed of these clusters as compared to a single sporangium (12). Based on laboratory and field observations from this study, we suggest that aerial dispersal of sporangia is relatively unimportant for $P$. capsici.

Unlike what is observed for $P$. infestans (2) and some downy mildew pathogens $(5,18)$, atmospheric $P$. capsici sporangial con-
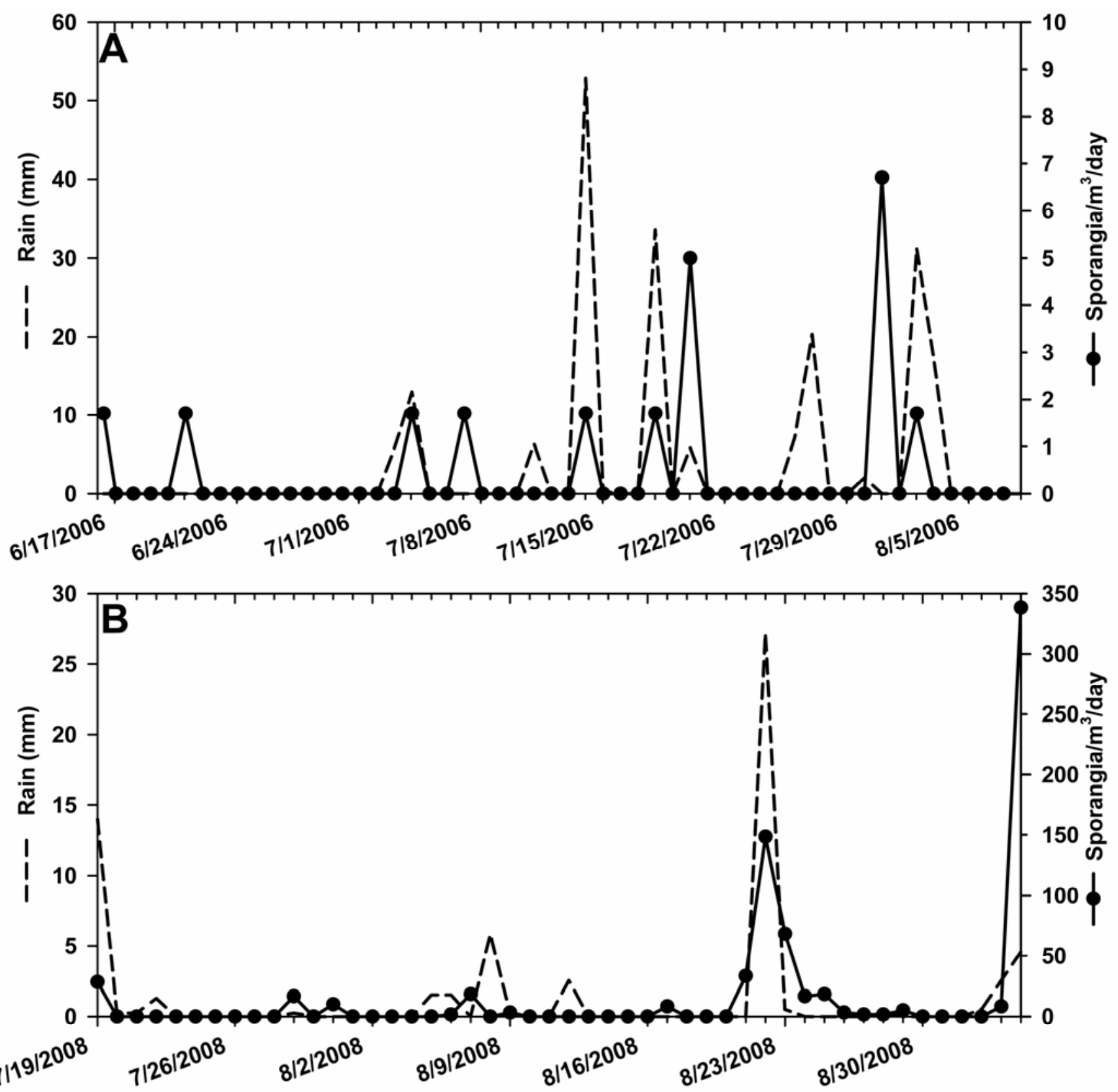

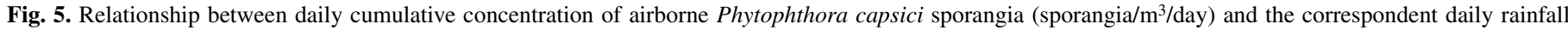

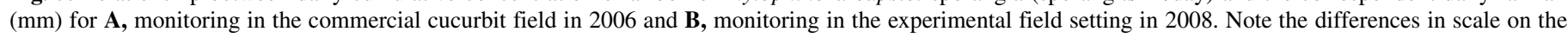
$y$ axes. 
centrations did not display a clear diurnal pattern in either field. Only rainfall was statistically associated with dispersal. Dispersal was sporadic, and sporangial dispersal was not always detected during rain events at either sampling site. This could be explained by sporangia wash-out during rainy or wet conditions, or sporangial detachment rates may have been low even when moisture was present. Our data is supported by a previous study by Schlub (32) that examined aerial dispersal of $P$. capsici in a pepper field during an active epidemic by using media-filled plates on stakes placed at different distances from sporulating host tissue. Schlub detected dispersal on 5 of 70 sampling occasions. Three of these dispersal events were associated with rain or overhead irrigation, and the remaining two occurred when plates were placed within $5 \mathrm{~cm}$ of host tissue with actively sporulating $P$. capsici (32).

Irrigation water infested with $P$. capsici can initiate an epidemic in a field lacking a previous history of infestation (14). Many studies have demonstrated the importance of water in the development and spread of disease caused by $P$. capsici $(6,28,32)$. In this study, we directly observed that sporangia will readily detach and be transported in water combined with capillary force. It is possible that the observed detachment and subsequent dispersal could be an artifact of tissue manipulation in setting up the samples. We maintain that this is unlikely since dispersal was never observed from tissue with $P$. capsici sporangia that was subjected to direct wind, although this tissue was manipulated in a similar fashion. The ability of water to detach and transport sporangia underscores the importance of water as the primary mechanism of pathogen dispersal.

It is known that wind has the potential to move microbes long distances, either as spores or in conjunction with soil particles. While it may be tempting to assume that long-distance atmospheric transport of inoculum is responsible for the sudden appearance of plant diseases in places far from areas of known pathogen establishment, it also important to remember that alternative pathways for pathogen transport exist, such as human-mediated transport (1). Since long-distance dispersal of sporangia via wind is unlikely, preventing long-distance human-mediated transport of $P$. capsici via infested soil and water and infected plant material is key. The current management strategies of exclusion, cultural control, host resistance, and fungicides and fumigants are still warranted in light of this study. Growers can circumvent longdistance spread of the pathogen by cleaning equipment between fields, not spreading cull fruit onto fields, and avoiding the use of surface water that may be contaminated with $P$. capsici to irrigate healthy crops $(14,17)$. Water is known to be a key factor in local spread of $P$. capsici spores and in the development of epidemics $(6,28)$. Water may be managed within a field by planting into well-drained fields, using raised beds, using black plastic mulch, trellising cucurbit plants, irrigating sparingly and using trickle irrigation. While it is important to use a multifaceted approach to manage the diseases caused by $P$. capsici, managing water appears paramount in light of the results of this as well as other studies (17).

\section{ACKNOWLEDGMENTS}

This research is based upon work supported by the USDA CSREES Special Research Grant under Award No. 2006-34572-16902; the USDA CSREES Special Research Grant under Award No. 2008-34572-19339; the Michigan Agricultural Experiment Station Hatch Project 01966; and the Pickle and Pepper Research Committee of MSU, Pickle Packers International, Inc. This study was also supported by a grant from the New York State Department of Agriculture and Markets and the NY State Agricultural Experiment Station Hatch Project 625-405. We thank P. Zaini, L. De La Fuente, K. Myers, H. Lange, and A. Camp for their assistance.

\section{LITERATURE CITED}

1. Aylor, D. E. 2003. Spread of plant disease on a continental scale: Role of aerial dispersal of pathogens. Ecology 84:1989-1997.

2. Aylor, D. E., Fry, W. E., Mayton, H., and Andrade-Piedra, J. L. 2001. Quantifying the rate of release and escape of Phytophthora infestans sporangia from a potato canopy. Phytopathology 91:1189-1196.

3. Bernhardt, E. A., and Grogan, R. G. 1982. Effect of soil matric potential on the formation and indirect germination of sporangia of Phytophthora parasitica, Phytophthora capsici, and Phytophthora cryptogea. Phytopathology 72:507-511.

4. Brockwell, P. J., and Davis, R. A. 2002. Introduction to Time Series and Forecasting. Springer-Verlag, New York.

5. Byrne, J. M., Hausbeck, M. K., and Sconyers, L. E. 2005. Influence of environment on atmospheric concentrations of Peronospora antirrhini sporangia in field-grown snapdragon. Plant Dis. 89:1060-1066.

6. Cafe-Filho, A. C., Duniway, J. M., and Davis, R. M. 1995. Effects of the frequency of furrow irrigation on root and fruit rots of squash caused by Phytophthora capsici. Plant Dis. 79:44-48.

7. Cox, A. E., and Large, E. C. 1960. Potato blight epidemics throughout the world. USDA ARS Handbook No. 174 U.S. Government Printing Office, Washington, D.C.

8. Davidson, C. R., Carroll, R. B., Evans, T. A., Mulrooney, R. P., and Kim, S. H. 2002. First report of Phytophthora capsici infecting lima bean (Phaseolus lunatus) in the Mid-Atlantic region. Plant Dis. 86:10491052.

9. De Bary, A. 1887. Comparative Morphology and Biology of the Fungi, Mycetozoa, and Bacteria. Oxford University Press, London, UK.

10. De La Fuente, L., Montane, E., Meng, Y., Li, Y., Burr, T. J., Hoch, H. C., and $\mathrm{Wu}, \mathrm{M}$. 2007. Assessing adhesion forces of type I and type IV pili of Xylella fastidiosa bacteria using a microfluidic flow chamber. Appl. Environ. Microbiol. 73:2690-2696.

11. Erwin, D. C., and Ribeiro, O. K. 1996. Phytophthora Diseases Worldwide. American Phytopathological Society, St. Paul, MN

12. Ferrandino, F. J., and Aylor, D. E. 1984. Settling speed of clusters of spores. Phytopathology 74:969-972.

13. French-Monar, R. D., Jones, J. B., and Roberts, P. D. 2006. Characterization of Phytophthora capsici associated with roots of weeds on Florida vegetable farms. Plant Dis. 90:345-350.

14. Gevens, A. J., Donahoo, R. S., Lamour, K. H., and Hausbeck, M. K. 2007. Characterization of Phytophthora capsici from Michigan surface irrigation water. Phytopathology 97:421-428.

15. Gevens, A. J., and Hausbeck, M. K. 2004. Phytophthora capsici isolated from snap bean is pathogenic to cucumber fruit and soybean. (Abstr.) Phytopathology 95(suppl.):S162.

16. Harvey, A. C. 1990. The Econometric Analysis of Time Series, 2nd ed. Phillip Allan, New York.

17. Hausbeck, M. K., and Lamour, K. H. 2004. Phytophthora capsici on vegetable crops: Research progress and management challenges. Plant Dis. $88: 1292-1303$.

18. Hildebrand, P. D., and Sutton, J. C. 1982. Weather variables in relation to an epidemic of onion downy mildew. Phytopathology 72:219-224.

19. Hirst, J. M. 1953. Changes in atmospheric spore content: Diurnal periodicity and the effects of weather. Trans. Br. Mycol. Soc. 36:375393.

20. Hirst, J. M. 1958. New methods for studying plant disease epidemics. Outlook Agric. 2:16-26.

21. Hirst, J. M. 1959. Spore liberation and dispersal. Pages 529-538 in: Plant Pathology: Problems and Progress 1908-1958. C. S. Holton, G. W. Fischer, R. W. Fulton, H. Hart, and S. E. A. McCallan, eds. American Phytopathological Society, St. Paul, MN.

22. Lamour, K. H., and Hausbeck, M. K. 2001. Investigating the spatiotemporal genetic structure of Phytophthora capsici in Michigan. Phytopathology 91:973-980.

23. Lamour, K. H., and Hausbeck, M. K. 2002. The spatiotemporal genetic structure of Phytophthora capsici in Michigan and implications for disease management. Phytopathology 92:681-684.

24. Murray, F. W. 1967. On the computation of saturated vapor pressure. J. Appl. Meterol. 6:203-204.

25. Quesada-Ocampo, L. M., Fulbright, D. W., and Hausbeck, M. K. 2009. Susceptibility of Fraser fir to Phytophthora capsici. Plant Dis. 93:135-41.

26. Ristaino, J. B., and Gumpertz, M. L. 2000. New frontiers in the study of dispersal and spatial analysis of epidemics caused by species in the genus Phytophthora. Annu. Rev. Phytopathol. 38:541-576.

27. Ristaino, J. B., and Johnston, S. A. 1999. Ecologically based approaches to management of Phytophthora blight on bell pepper. Plant Dis. 83:10801088.

28. Ristaino, J. B., Larkin, R. P., and Campbell, C. L. 1993. Spatial and temporal dynamics of Phytophthora epidemics in commercial bell pepper fields. Phytopathology 83:1312-1320. 
29. Ristaino, J. B., Larkin, R. P., and Campbell, C. L. 1994. Spatial dynamics of disease symptom expression during Phytophthora epidemics in bell pepper. Phytopathology 84:1015-1024.

30. Saint-Jean, S., Testa, A., Kamoun, S., and Madden, L. V. 2005. Use of a green fluorescent protein marker for studying splash dispersal of sporangia of Phytophthora infestans. Eur. J. Plant Pathol. 112:391-394.

31. Scherm, H., and van Bruggen, A. H. C. 1995. Concurrent spore release and infection of lettuce by Bremia lactucae during mornings with prolonged leaf wetness. Phytopathology 85:552-555.

32. Schlub, R. L. 1983. Epidemiology of Phytophthora capsici on bell pepper. J. Agric. Sci. 100:7-11.

33. Timmer, L. W., Zitko, S. E., Gottwald, T. R., and Graham, J. H. 2000. Phytophthora brown rot of citrus: Temperature and moisture effects on infection, sporangium production, and dispersal. Plant Dis. 84:157-163.

34. Waterhouse, G. 1963. Key to the Species of Phytophthora de Bary. Commonwealth Mycological Society, Kew, UK. 